\title{
Fractional Flow Reserve for Intermediate Coronary Artery Stenosis in Nepal
}

\author{
Mahesh Bhattarai ${ }^{1}$, Arun Maskey ${ }^{2}$, Ram Kishore Sah ${ }^{1}$, Himamshu Nepal $^{2}$, Rabindra Pandey ${ }^{2}$, Rikesh Tamrakar ${ }^{2}$, \\ Amit Agrawal ${ }^{1}$, Rabi Malla ${ }^{2}$, Rajib Rajbhandari', Chandra Mani Adhikari ${ }^{2}$, Yadav Kumar Dev Bhatta ${ }^{2}$ \\ 1 Deparrtment of Cardiology, National Academy of Medical Sciences, Bir Hospital, Kathmandu \\ 2 Department of Cardiology,Shahid Gangalal National Heart Centre, Bansbari, Kathmandu \\ Corresponding author: Mahesh Bhattarai, National Academy of Medical Sciences, Bir Hospital, Kathmandu, Nepal, Email: drmaheshbha@gmail.com
}

\begin{abstract}
Background and Aims: : Coronary angiogram detects anatomical lesion, however, has limited ability to assess physiological significance. Fractional flow reserve is used to determine functional significance of stenosis and is measured by the ratio of mean distal coronary pressure to mean aortic pressure during maximum hyperemia. Recently, fractional flow reserve was started in Nepal. This study intends to explore the extent of determination of hemodynamic significance of intermediate coronary stenosis by fractional flow reserve, thereby guiding revascularization.

Methods: Consecutive patients with intermediate lesion undergoing fractional flow reserve from July 2014 to March 2015 were included, if fractional flow reserve $\leq 0.80$ then considered to be significant and need for revascularization determined. The study subjects were divided into two groups, one having physiologically significant stenosis and another with physiologically non significant lesion and followed up to three months.

Results: Total forty four patients had fractional flow reserve done in fifty eight intermediate coronary artery lesions. The age ranged from 33 to 78 with the mean age of $58.25 \pm 10.08$ years. Majority of them $(75 \%)$ were male. Left anterior descending artery was commonest in $37(63.8 \%)$, followed by left circumflex $13(22.4 \%)$, then right coronary artery in $8(13.8 \%)$ target lesions. None of the patient had death, myocardial infarction or repeat revascularization during follow up. Out of 58 intermediate lesions assessed, $17(29.31 \%)$ had significant fractional flow reserve value, whereas $41(70.69 \%)$ had physiologically non significant lesion.

Conclusion: Around one third (29.31\%) of intermediate coronary artery stenosis are functionally significant by fractional flow reserve in the context of Nepal, thus it could be useful guide for optimal revascularization.
\end{abstract}

Key words: Fractional flow reserve, Intermediate coronary stenosis, Revascularization

\section{Introduction:}

Fractional flow reserve (FFR) is a method of assessing the functional significance of an intermediate coronary stenosis. ${ }^{1}$ Coronary angiography, being a luminogram, is limited in its ability to determine the physiological significance of stenosis, especially in intermediate coronary stenosis. ${ }^{2,3}$ This uncertainty may result in unnecessary revascularization of insignificant lesions or failure to revascularize the clinically significant ones.

FFR is determined by measurement of the coronary pressure, using a guide wire fitted with a micromanometer. ${ }^{4}$ FFR represents the extent to which maximal myocardial blood flow is limited by the presence of epicardial stenosis and can be measured by the ratio of mean distal coronary pressure $(\mathrm{Pd})$ to mean aortic pressure
$(\mathrm{Pa})$ during maximum hyperemia, usually induced by adenosine and represents the percentage of normal flow across a coronary stenosis. ${ }^{5}$

FFR assessment has been recently introduced in Nepal at Shahid Gangalal National Heart Centre. The present study explores the extent of hemodynamic significance of the intermediate coronary stenosis by FFR in the context of Nepal.

\section{Methods:}

Consecutive patients with one or more intermediate coronary artery stenosis undergoing FFR from July 2014 to March 2015 were included. The intermediate coronary stenosis was defined as the lesion having 
$50-70 \%$ stenosis by the visual estimation of the primary operator. The patient having acute coronary syndrome within seven days, left main disease, left ventricular hypertrophy with interventricular septum thickness more than $1.3 \mathrm{~cm}$, and those not giving informed consent were excluded from the study. The ethical clearance was taken from institutional review board of National Academy of Medical Sciences, Kathmandu and Shahid Gangalal National Heart Centre.

After introduction of artery sheath, guide catheter was engaged into the coronary ostium and the pressure wire zeroed and calibrated. Once the pressures recorded from the catheter tip and the pressure wire's micro manometer were identical, the wire was advanced to position the transducer distal to the lesion. The pressure waveforms were recorded at rest and during maximal hyperemia induced by intracoronary adenosine bolus. ${ }^{6}$ FFR was calculated as $\mathrm{Pd} / \mathrm{Pa}$ during hyperemia.

Angiographic and hemodynamic characteristics were analyzed and if FFR $\leq 0.80$ then considered significant and need for revascularization determined. The study subjects were divided into two groups, one group having physiologically significant stenosis and another group having physiologically non significant stenosis. The demographic variables, angiographic variable and procedural outcome were compared among groups, they were followed up at three months and monitored for the death, myocardial infarction and target lesion revascularization. The statistical analysis was carried on SPSS 16, categorical variable were analyzed with chi square test and independent sample $t$ test was used for the comparison of numerical variables with $p$ value less than 0.05 as the level of significance at $95 \%$ confidence interval.

\section{Results:}

Total forty four patients had fractional flow reserve done in fifty eight intermediate coronary artery lesions. The age ranged from 33 to 78 with the mean age of $58.25 \pm 10.08$ years. Majority of them $(75 \%)$ were male. The distribution of target lesion assessed showed that left anterior descending artery was commonest in $37(63.8 \%)$, followed by left circumflex artery $13(22.4 \%)$, then right coronary artery in $8(13.8 \%)$. Out of fifty eight intermediate lesions assessed, $17(29.31 \%)$ had significant fractional flow reserve value, requiring revascularization, whereas $41(70.69 \%)$ had physiologically non significant stenosis.

The baseline characteristics between the two groups, one group having physiologically significant stenosis and another group with physiologically non significant stenosis were similar as presented in table 1. The angiographic severity of coronary artery disease was comparable among the two groups as shown in table 2 .

\begin{tabular}{|c|c|c|c|}
\hline $\begin{array}{c}\text { Baseline } \\
\text { characteristics }\end{array}$ & $\begin{array}{c}\text { Group1 } \\
\text { FFR } \leq 0.8(\mathrm{n}=14)\end{array}$ & $\begin{array}{c}\text { Group2 } \\
\text { FFR }>0.8(\mathrm{n}=30)\end{array}$ & $\begin{array}{c}\mathrm{P} \\
\text { value }\end{array}$ \\
\hline Age (years) & $57.86 \pm 9.99$ & $58.43 \pm 10.28$ & 0.28 \\
\hline Age $\geq 60$ years & $7(50 \%)$ & $13(43.3 \%)$ & 0.67 \\
\hline Sex male & $10(71.4 \%)$ & $23(76.6 \%)$ & 0.70 \\
\hline $\begin{array}{l}\text { Presentation: } \\
\text { Stable angina }\end{array}$ & 4 & 12 & \multirow{3}{*}{0.45} \\
\hline $\begin{array}{l}\text { Unstable } \\
\text { angina(>1week) }\end{array}$ & 4 & 4 & \\
\hline $\begin{array}{l}\text { Previous } \\
\text { myocardial } \\
\text { infarction }\end{array}$ & 6 & 14 & \\
\hline Hypertension & $9(64 \%)$ & $15(50 \%)$ & 0.37 \\
\hline $\begin{array}{l}\text { Diabetes } \\
\text { Mellitus }\end{array}$ & $4(28.5 \%)$ & $8(26.6 \%)$ & 0.89 \\
\hline Smoking & $9(64.3 \%)$ & $13(43.3 \%)$ & 0.19 \\
\hline $\begin{array}{l}\text { Family h/o } \\
\text { CAD }\end{array}$ & $2(14.2 \%)$ & $3(10 \%)$ & 0.67 \\
\hline Dyslipidemia & $4(28.5 \%)$ & $7(23.3 \%)$ & 0.7 \\
\hline
\end{tabular}

\begin{tabular}{|c|c|c|c|}
\hline & $\begin{array}{l}\mathrm{FFR} \leq 0.8 \\
(\mathrm{n}=14)\end{array}$ & $\begin{array}{l}\mathrm{FFR}>0.8 \\
(\mathrm{n}=30)\end{array}$ & $\begin{array}{l}\mathrm{P} \\
\text { value }\end{array}$ \\
\hline \multicolumn{3}{|l|}{ Severity of CAD } & \multirow{4}{*}{0.54} \\
\hline Single vessel disease & 4 & 13 & \\
\hline Double vessel disease & 6 & 12 & \\
\hline Triple vessel disease & 4 & 5 & \\
\hline
\end{tabular}

Patient were followed up at one month and three months. Death, myocardial infarction or target lesion revascularization occurred in none of the patient in both the groups. However one patient with non significant lesion in left circumflex and significant lesion in right coronary artery for which percutaneous coronary intervention was done, presented with repeated angina class II, repeat angiogram showed patent stent and was further stabilized with medical management.

\section{Discussion}

The present study explores the hemodynamic significance of intermediate coronary artery stenosis in the context of Nepal and their short term follow up. Total 44 patients had fractional flow reserve assessment done in 58 intermediate coronary artery lesions. 
The age ranged from 33 to 78 with the mean age of $58.25 \pm 10.08$ years. Majority of them $(75 \%)$ were male. Similar demographic profile was studied in one study from India with age being $59.9 \pm 10.5$ and male being 47(79.7 $\%)$ among 59 study population. ${ }^{14}$

The group having hemodynamic significant lesion had age of $57.86 \pm 9.99$ and other with non significant lesion had age of $58.43 \pm 10$ year. Similar age group was included in another study from India age of $60.6 \pm 10.3$ in hemodynamic significant and $61.2 \pm 10.2$ years in hemodynamic non significant group. ${ }^{7}$

The distribution of target lesion assessed showed that left anterior descending artery (LAD) was commonest in $37(63.8 \%)$, followed by left circumflex (LCX) $13(22.4 \%)$, then right coronary (RCA) in $8(13.8 \%)$. In the study from India, RCA was commonest $42(40.39 \%)$, followed by LCX 37(35.58\%), and then LAD 25(24.03\%). Another study showed distribution of lesion was LAD $57 \%$, followed by RCA $18 \%$ and LCX $14 \% .{ }^{8}$

COURAGE trial demonstrated that in patient with stable coronary artery disease treatment with PCI was not associated with a difference in death or MI compared with the medical therapy through 5 year follow up but was associated in high cost. ${ }^{9}$ Some studies have demonstrated the utility of FFR. It is a lesion specific index of epicardial conductance, which is independent of changes in hemodynamic conditions like systemic blood pressure or heart rate. ${ }^{10}$ The DEFER Study demonstrated in stable ischemic heart disease at five-year follow-up, the deferred group, considering FFR 0.75 across an intermediate stenosis as a cut off, had rate of death or myocardial infarction that was less than half the rate in the PCI group. ${ }^{11}$ Fractional Flow Reserve versus Angiography for Multivessel Evaluation (FAME) trial ${ }^{12}$ showed that in patients with multivessel disease (including stable ischemic heart disease, unstable angina, and NSTEMI) composite rate of death, myocardial infarction or repeat revascularization at 1 year, was significantly lower $(13.2 \%$ vs. $18.3 \%, \mathrm{P} 0.02$ ) in patients who received FFR-guided PCI compared to angiography guided PCI. An economic evaluation verified that FFR-guided PCI is a cost-saving strategy ${ }^{13}$, with fewer stents deployed and less contrast used. FIND study had showed that FFR is cost effective. ${ }^{14}$

Fractional Flow Reserve versus Angiography for Multivessel Evaluation 2 (FAME 2) trial ${ }^{15}$ randomized patients with single or multivessel stable ischemic heart disease to FFR-guided PCI with cut off value of 0.80 with optimal medical therapy or optimal medical therapy alone. There was a significantly greater rate of urgent revascularization in the medical therapy arm $(11.1 \%$ vs. $1.6 \% \mathrm{P}<0.001) .{ }^{15}$ The rate of composite of death from any cause, nonfatal myocardial infarction, or urgent revascularization within 2 years was significantly lower in the PCI group than in the medical-therapy group $(8.1 \%$ vs. $19.5 \% ; \mathrm{P}<0.001)$. This reduction was driven by a lower rate of urgent revascularization in the PCI group (4.0\% vs. $16.3 \% ; \mathrm{P}<0.001)^{1}$

TheACCF/AHA and SCAI task force on coronary revascularization has endorsed FFR in intermediate lesion of $50-70 \%$ as class II a recommendation. Even angiographic severe lesion of $71-90 \%$ still have $20 \%$ FFR negative results , expert consensus has suggested expansion of its use to all coronary stenosis $\leq 90 \% .{ }^{17}$ ESC Guidelines on myocardial revascularization in 2014- has recommended FFR guided revascularization for stable angina when evidence of ischemia is not available, as Class I recommendation. ${ }^{18}$ FFR has a continuous and independent relationship with outcome modulated by revascularization procedure. The patient with lower FFR value will have large absolute benefit with revascularization. ${ }^{8}$

In the present study out of fifty eight intermediate lesions assessed, 17(29.31\%) had significant fractional flow reserve value, requiring revascularization, whereas $41(70.69 \%)$ had functionally non significant stenosis with FFR $>0.8$. In one study 74 patient with 104 intermediate lesion were assessed by FFR and $43(41.3 \%)$ lesions had hemodynamic significance and 61(58.7\%) lesions had no hemodynamic significance. ${ }^{7}$ In another study coronary artery lesions with angiographic diameter stenosis $\geq 50 \%$ and FFR >0.80(' visual-functional mismatches") were seen in $57 \%$ of non-left main lesions and in $35 \%$ of the left main lesions. ${ }^{19}$ Some of the independent predictors for mismatch in that study were advance age, non-left anterior descending artery location, short lesion length, smaller plaque burden, absence of plaque rupture, and greater lumen diameter ${ }^{19}$.

In the present study two groups were followed up for three months. Death, myocardial infarction or target lesion revascularization occurred in none of the patient in both the groups. Similar results were observed in other studies, in one study there were no major events at a mean follow up of $11 \pm 5$ months 14 and another study had low repeat revascularization number $1(2.5 \%)$ in hemodynamic significant group and $1(2.85 \%)$ in hemodynamic non significant lesion which underwent revascularization. ${ }^{7}$

The present study has small number of patient and short duration of follow up. However, this is the first study from the country, FFR has been recently introduced and this centre is the only centre with this facility in the country. Moreover, further study with longer follow up and larger number of patient may show more clinical event rate.

\section{Conclusion}

The present study has shown that around one third (29.31\%) of the intermediate coronary artery stenosis are haemodynamically significant by fractional flow reserve in the context of Nepal, thus it could be a useful tool to guide for optimal coronary revascularization. 


\section{References}

1. Christou MA, Siontis GC, Katritsis DG,et al. Metaanalysis of fractional flow reserve versus quantitative coronary angiography and noninvasive imaging for evaluation of myocardial ischemia. Am J Cardiol 2007; 99: 450-456.

2. White CW, Wright CB, Doty DB, et al. Does visual interpretation of the coronary arteriogram predict the physiologic importance of a coronary stenosis? N Engl J Med 1984; 310:819-24.

3. Yong AS, Ng AC, Brieger D,et al. Threedi-mensional and two-dimensional quantitative coronary angiography, and their prediction of reduced fractional flow reserve. Eur Heart J 2011; 32:345-53.

4. Pijls NHJ, van Son JAM, Kirkeeide RL, et al. Experimental basis of determining maximum coronary, myocardial, and collateral blood flow by pressure measurements for assessing functional stenosis severity before and after percutaneous transluminal coronary angioplasty. Circulation 1993;87:1354-1367.

5. Pijls NH, De Bruyne B, Peels K, et al. Measurement of fractional flow reserve to assess the functional severity of coronary-artery stenoses. $\mathrm{N}$ Engl J Med 1996; 334:1703-8.

6. Casella G, Leibig M, Schiele TM, et al. Are high doses of intracoronary adenosine an alternative to standard intravenous adenosine for the assessment of fractional flow reserve? AmHeartJ 2004; 148:590-595.

7 Kumar A ,Kumar P, Goel PK. Fractional flow reserve for all coronary lesions with intermediate stenosis, a step towards optimal PCI- single centre experience in India. Journal of Indian college of cardiology 2014;2: 101-104.

8. Johnson N P, Tóth G G, Lai D,et al. Prognostic Value of Fractional Flow Reserve linking physiologic severity to clinical outcomes. J Am Coll Cardiol 2014; 64: 1641-54.

9. William E. Boden, Robert A. O'Rourke, Koon K. Te, et al. Optimal Medical Therapy with or without PCI for Stable Coronary Disease. N Engl J Med 2007; 356:1503-1516.

10 De Bruyne B, Bartunek J, Sys SU, et al.Si $\neg$ multaneous coronary pressure and flow velocity measurements in hu $\neg$ mans: feasibility, reproducibility, and hemodynamic dependence of coronary flow velocity reserve, hyperemic flow versus pressure slope index, and fractional flow reserve. Circulation .1996; 94:1842-9.

11. Pijls NH, van Schaardenburgh $\mathrm{P}$, Manoharan $\mathrm{G}$, et al. Percutaneous coronary intervention of functionally non significant stenosis: 5-year followup of the DEFER Study. J Am Coll Cardiol 2007; 49: 2105-2111.

12. Tonino PA, Fearon WF, De Bruyne B, et al. Angiographic versus func $\neg$ tional severity of coronary artery stenoses in the FAME Study frac $\neg$ tional flow reserve versus angiography in multivessel evaluation. J Am Coll Cardiol 2010; 55:2816-21.

13. Fearon WF, Bornschein B, Tonino PA, et al. Economic evaluation of fractional flow reserveguided percutaneous coronary intervention in patients with multivessel disease. Circulation 2010; 122:2545-2550.

14. Sengottuvelu, G., Chakravarthy, B., Rajendran, R. et al. (2014), Clinical usefulness and cost effectiveness of fractional flow reserve among Indian patients (FIND study). Cathet. Cardiovasc. Intervent.. doi: 10.1002/ccd.25517

15 De Bruyne B, Pijls NH, Kalesan B, et al. Fractional flow reserve-guided PCI versus medical therapy in stable coronary disease. N Engl J Med 2012; 367 : 991-1001.

16 De Bruyne B, Fearon WF, Pijls NH, et al. Fractional Flow Reserve-Guided PCI for Stable Coronary Artery Disease. N Engl J Med 2014; 367 : 991-1001.

17. Lofti A, Jeremias A, Fearon WF,et al. Expert consensus statement on the use of fractional flow reserve, intravascular ultrasound, and optical coherence tomography: A consensus statement of the society of the cardiovascular angiography and interventions. Catherter Cardiovasc Interv 2014; 83:509-518.

18. Windecker S, Kolh P, Alfonso F, et al. 2014 ESC/EACTS Guidelines on myocardial revascularization. Eur Heart J .2014; 35 (37): 25412619.

19. Park SJ, Kang SJ, Ahn JM, et al. Visual-Functional Mismatch Between Coronary Angiography and Fractional Flow Reserve. J Am Coll Cardiol Intv 2012;5:1029-1036.
Cite this article as: Mahesh Bhattarai, Arun Maskey, Ram Kishore Sah,et al. Fractional Flow Reserve for Intermediate Coronary Artery Stenosis in Nepal. Nepalese Heart Journal 2015;12(2):69-72. 